\title{
PENERAPAN METODE POLINOM NEWTON GREGORY MAJU DAN POLINOM NEWTON GREGORY MUNDUR DENGAN METODE HAMILTON-PERRY DALAM MEMPREDIKSI JUMLAH PENDUDUK SUMATERA UTARA.
}

\author{
Ratna Wahyuni ${ }^{1)}$ dan Indah Simamora ${ }^{2)}$ \\ 1,2) Universitas Quality Berastagi \\ e-mail: ratnawahyuni8@gmail.com
}

\begin{abstract}
ABSTRAK
Kebutuhan data kependudukan merupakan hal mutlak yang yang harus dipenuhi oleh BPS, namun sumber data kependudukan terlengkap bersumber dari hasil sensus penduduk. Sementara itu, pelaksanaan sensus penduduk hanya 10 tahun sekali karena membutuhkan biaya, waktu, dan tenaga. Prediksi penduduk pada tahun berikutnya dalam tiap periode sensus perlu dilakukan untuk mengetahui selisih pertambahan penduduk pada tahun tersebut. Oleh karena itu peneliti tertarik mengkaji "Penerapan Metode Polinom Newton Gregory Maju dan Polinom Newton Gregory Mundur dengan Metode HamiltoPerry dalam Memprediksi Jumlah Penduduk Sumatera Utara." Metode yang digunakan dalam penelitian ini adalah studi literature dimana sumber data yang digunakan adalah data sekunder dan dalam hal ini peneliti akan menganalisis diantara tiga periode sensus. Tujuan penelitian ini adalah memperoleh hasil yang efektif dari ketiga metode tersebut sehingga dapat dijadikan sebagai aplikasi alternative bagi Badan pusat Statistik (BPS) provinsi Sumatera Utara untuk memprediksi jumlah penduduk pada tahun diantara sensus. Untuk Hamilton-perry, penerapan metodenya mudah dilakukan karena proses perhitungannya yang tidak rumit dan data yang digunakan sebagai bahan prediksi sangat minim, tetapi nilai prediksi menghasilkan nilai tidak bulat sehingga perlu dibulatkan namun ketika nilai sudah dibulatkan terdapat selisih antara nilai tidak dibulatkan dengan nilai yang dibulatkan secara agrgat. Oleh karena itu dibutuhkan adjustment pada nilai hasil pembulatan berdasarkan nilai tidak dibulatkan. Kemudian berdasarkan uji coba agregat prediksi penduduk menggunakan metode Hamilton-perry menhgasilkan nilai yang lebih tinggi daripada nilai aktualnya. Untuk metode polinom newton gregory maju dan polinom newton gregory mundur diperoleh masing-masing galat relatif totalnya adalah $\sum \varepsilon_{R}=0,31412327$ dan $\sum \varepsilon_{R}=0,3522818$ dan. Dari kedua galat relatif tersebut diketahui bahwa galat total untuk metode polinom newton gregory maju lebih kecil dari galat total untuk metode polinom newton gregory mundur. Dengan demikian metode polinom newton gregory maju memiliki akurasi yang lebih baik
\end{abstract}

\section{Kata Kunci : Polinom Newton Gregory; Hamilton_Perry}

\begin{abstract}
Population data needs are absolute things that must be met by BPS, but the most complete source of population data comes from population census results. Meanwhile, the implementation of the population census is only once every 10 years because it requires cost, time, and energy. Population prediction in the following year in each census period needs to be done to determine the difference in population growth in that year. Therefore, researchers are interested in studying the "Application of the Advanced Newton Gregory Polynomic Method and the Newton Gregory Backward Polynomic with the Hamilto-Perry Method in Predicting the Population of North Sumatra." this case the researcher will analyze between the three census periods. The purpose of this study is to obtain effective results from the three methods so that it can be used as an alternative application for the Central Statistics Agency (BPS) of North Sumatra province to predict the population in the year between the census. For Hamilton-perry, the application of the method is easy to do because the calculation process is uncomplicated and the data used as prediction material is very minimal, but the predicted value produces a non-rounded value so it needs to be rounded but when the value has been rounded there is a difference between the value not rounded to the rounded value aggressively. Therefore we need an adjustment to the value of rounding results based on the value not rounded. Then based on an aggregate trial of population prediction using the Hamilton-Perry method it produces a value that is higher than the actual value. For the advanced newton gregory polynomic
\end{abstract}


method and the backward newton gregory polynomic each obtained total relative error is $\sum \varepsilon_{R}=$ 0,31412327 and $\sum \varepsilon_{R}=0,3522818$. From the two relative errors it is known that the total error for the advanced Newtonton polynomial method is smaller than the total error for the backward Newtonian polynomial method. Thus the Newton Newton method of advanced polynomial has better accuracy

Keywords: Newton Gregory Polynomics; Hamilton_Perry

\section{PENDAHULUAN}

Pertumbuhan Penduduk merupakan bertambahnya jumlah penduduk suatu daerah yang disebabkan oleh factor demografi ( fertilitas, mortalitas dan migrasi ) dan factor nondemografi ( kesehatan dan pendidikan). Untuk mengetahui tingkat pertumbuhan penduduk biasanya dilakukan pendataan yang dikenal dengan sensus penduduk.

Sensus penduduk adalah pencatatan penduduk yang dilakukan pada kurun waktu tertentu. Biasanya sensus penduduk dilakukan setiap lima tahun atau sepuluh tahun.

Sensus penduduk ini dilakukan karena berfungsi untuk:

1. Mengetahui jumlah penduduk seluruhnya.

2. Mengetahui pertumbuhan penduduk.

3. Mengetahui persebaran dan kepadatan penduduk.

4. Mengetahui komposisi penduduk.

5. Mengetahui besarnya urbanisasi.

6. Merencanakan pembangunan bangsa dan negara.

Di Indonesia pada umumnya dan pada khususnya di Sumatera Utara, pelakasanaan sensus penduduk dilakukan oleh Badan Pusat Statistik (BPS) provinsi Sumatera Utara dalam kurun waktu 10 tahun sekali. Prediksi penduduk pada tahun berikutnya dalam tiap periode sensus perlu dilakukan untuk mengetahui selisih pertambahan penduduk pada tahu tersebut. (BPS, 2003)

Untuk memprediksi jumlah penduduk bisa dengan menggunakan metode numeric yaitu Polinom newton Gregory merupakan kasus khusus dari polinom newton dari titiktitik yang berjarak sama. Untuk titik-titik yang berjarak sama, rumus polinom newton menjadi lebih sederhana. Selan itu, table selisih terbaginya pun lebih mudah dibentuk. Disini table tersebut dinamakan table selisih. Ada dua macam table selisih yaitu: table selisih maju ( forward difference) dan table selisih mundur (backward difference). Karena ada dua macam polinom newton Gregory yaitu polinom newton Gregory maju dan polinom newton Gregory mundur. (Munir,R. 2003)

Sementara menurut (Muhammad Fajar, 2017), penerapan metode Hamilton-perry untuk proyeksi penduduk lebih mudah karena proses perhitungannya tidak rumit dan data yang digunakan sebagai bahan proyeksi sangat minim (hanya membutuhkan data dari dua sensus penduduk).

Oleh karena itu peneliti tertarik mengkaji "Penerapan Metode Polinom Newton Gregory Maju dan Polinom Newton Gregory Mundur dengan Metode Hamilton-perry dalam Memprediksi Jumlah Penduduk Sumatera Utara." Dalam hal ini peneliti akan menganalisis diantara tiga periode sensus. Selanjutnya untuk melihat perbandingan kelayakan atau akurasi hasil prediksi ini, akan dikaji taksiran galat dari ketiga metode tersebut. Harapan peneliti adalah agar dapat dijadikan sebagai aplikasi alternatif bagi Badan Pusat Statistik (BPS) provinsi Sumatera Utara untuk memprediksi jumlah penduduk pada tahun diantara sensus.

\section{Permasalahan penelitian}

Berdasarkan Latar Belakang tersebut, adapun permaslahan penelitian ini adalah:

1. Bagaimana penerapan metode polinom newton Gregory maju dan polinom newton Gregory mundur dengan metode HamiltonPerry dalam memprediksi jumlah penduduk Sumatera Utara?

2. Diantara metode polinom newton Gregory maju dan polinom newton Gregory mundur serta Metode Hamilton-Perry, metode 
manakah yang perhitungannya lebih akurat dalam memprediksi jumlah penduduk di Sumatera Utara.

\section{Tujuan khusus}

Adapun manfaat dan tujuan penelitian ini adalah:

1. Untuk menerapkan metode polinom newton Gregory maju dan polinom newton Gregory mundur serta metode HamiltonPerry dalam memprediksi jumlah penduduk.

2. Untuk mengetahui jumlah penduduk pada tahun diantara sensus.

3. Untuk dijadikan sebagai aplikasi alternatif bagi Badan Pusat Statistik (BPS) untuk memprediksi jumlah penduduk.

\section{METODE PENELITIAN}

Langkah-langkah yang dilakukan dalam penelitian ini:

1. Memulai penelitian

2. Melakukan pengambilan data pada Badan Pusat Statistik Sumatera Utara

3. Memodelkan polinom newton gregory maju, polinom gregory mundur dan metode HamiltonPerry

4. Melakukan prediksi banyaknya penduduk Sumatera Utara secara manual

5. Perhitungan Galat Relatif

6. Menyimpulkan Hasil Penelitian

7. Selesai

\section{HASIL DAN PEMBAHASAN}

\section{Metode Polinom Newton Gregory Maju dan Polinom Newton Gregory Mundur}

Prediksi jumlah penduduk Sumatera Utara menggunakan metode Polinom Newton Gregory Maju diselesaikan menggunakan persamaan: $\quad P_{3}=f_{0}+\frac{s}{1 !} \Delta f_{0}+$ $\frac{s(s-1)}{2 !} \Delta^{2} f_{0}+\frac{s(s-1)(s-2)}{3 !} \Delta^{3} f_{0}$ dengan $\quad \Delta f_{0}, \Delta^{2} f_{0}, \Delta^{3} f_{0}$ ditentukan melalui table selisih maju polinom newton gregory maju dengan menggunakan data sensus penduduk Badan Pusat Statistik Sumatera Utara dengan jarak sensus 10 tahun untuk periode 1980 sampai dengan 2010. Data tersebut dapat dilihat pada tabel 1 .

Tabel 1. Data Penduduk dari Badan Pusat Statistik Sumatera Utara

\begin{tabular}{|r|r|r|r|r|r|}
\hline Tahun & Banyak Penduduk & Tahun hyak Penduduk & Tahun & Banyak Penduduk \\
\hline 1980 & 8360894 & 1991 & 10454686 & 2002 & 11968700 \\
\hline 1981 & 8526204 & 1992 & 10685200 & 2003 & 12131200 \\
\hline 1982 & 8791514 & 1993 & 10813400 & 2004 & 12293600 \\
\hline 1983 & 9056824 & 1994 & 10981100 & 2005 & 12452800 \\
\hline 1984 & 9322134 & 1995 & 11145300 & 2006 & 12605700 \\
\hline 1985 & 9422137 & 1996 & 11306300 & 2007 & 12760700 \\
\hline 1986 & 9442984 & 1997 & 11463400 & 2008 & 12914600 \\
\hline 1987 & 9463831 & 1998 & 11754100 & 2009 & 13066600 \\
\hline 1988 & 9484678 & 1999 & 11955400 & 2010 & 13217600 \\
\hline 1989 & 9505525 & 2000 & 11959700 & & \\
\hline
\end{tabular}




\begin{tabular}{|l|l|l|l|l|l|}
\hline 1990 & 10256027 & 2001 & 11963400 & & \\
\hline
\end{tabular}

Sedangkan untuk metode polinom newton gregory mundur menggunakan persamaan $Q_{3}=f_{0}+\frac{s}{1 !} \nabla f_{0}+\frac{s(s-1)}{2 !} \nabla^{2} f_{0}+$ $\frac{s(s-1)(s-2)}{3 !} \nabla^{3} f_{0} \quad$ dengan $\nabla f_{0}, \quad \nabla^{2} f_{0}, \quad \nabla^{3} f_{0}$ ditentukan melalui tabel selisih mundur polinom newton gregory mundur dengan menggunakan data yang sama dengan metode polinom newton gregory maju yaitu bersumber dari Badan Pusat Statistik Sumatera Utara. Pada penelitian ini digunakan persamaan galat relative untuk mengetahui seberapa besar galat atau error yang dihasilkan dari masing-masing metode. Misalkan $\hat{a}$ adalah nilai hampiran ( data prediksi dengan menggunakan metode polinom newton gregory maju dan polinom newton gregory mundur) dan $a$ adalah nilai sejati (data dari BPS), maka galat merupakan selisih antara nilai sejati dengan nilai hampiran dinyatakan dengan persamaan $\varepsilon=a-\hat{a}$. Pada penelitian ini, tanda positif dan negative tidak dipertimbangkan sehingga galat mutlak dapat didefinisikan sebagai $|\varepsilon|=|a-\hat{a}|$ kemudian untuk mencegah nilai galat $\varepsilon$ bernilaibesar maka harus dinormalkan terhadap nilai sejatinya $\varepsilon_{R}=\frac{\varepsilon}{a}$ yang disebut galat relatif. Menganalisi galat sangat penting didalam perhitungan yang menggunakan metode numeric, semakin kecil galatnya maka semakin teliti solusi numerik yang didapatkan. Berikut data prediksi dari kedua metode polinom newton gregory maju dan polinom newton gregory mundur yang ditampilkan pada tabel 2 dan tabel 3.

Tabel 2. Prediksi banyaknya penduduk Sumatera Utara beserta Galat Relatif dengan menggunakan metode polinom newton gregory maju.

\begin{tabular}{|c|c|c|c|c|c|}
\hline Tahun & $\begin{array}{r}\text { Prediksi } \\
\text { Banyaknya } \\
\text { penduduk }\end{array}$ & Galat Relatif & Tahun & $\begin{array}{r}\text { Prediksi } \\
\text { banyaknya } \\
\text { penduduk }\end{array}$ & Galat Relatif \\
\hline 1981 & 8551775 & 0,002999107 & 1997 & 11495404 & 0,002791842 \\
\hline 1982 & 8743030 & 0,005514864 & 1998 & 11654626 & 0,008462919 \\
\hline 1983 & 8934405 & 0,01351677 & 1999 & 11809391 & 0,01221281 \\
\hline 1984 & 9125696 & 0,02107221 & 2001 & 12085490 & 0,01020529 \\
\hline 1985 & 9316498 & 0,01121179 & 2002 & 12211280 & 0,02026787 \\
\hline 1986 & 9506707 & 0,006748185 & 2003 & 12337070 & 0,01697029 \\
\hline 1987 & 9696019 & 0,02453425 & 2004 & 12462860 & 0,01376814 \\
\hline 1988 & 9884178 & 0,04212057 & 2005 & 12588650 & 0,01090919 \\
\hline 1989 & 10070932 & 0,05948193 & 2006 & 12714440 & 0,008626256 \\
\hline 1991 & 10446453 & 0,0007874938 & 2007 & 12840230 & 0,006232417 \\
\hline 1992 & 10632422 & 0,004939355 & 2008 & 12966020 & 0,00398154 \\
\hline 1993 & 10813934 & 0,00004938317 & 2009 & 13091810 & 0,001929347 \\
\hline 1994 & 10990988 & 0,0009004562 & & & \\
\hline 1995 & 11163584 & 0,001640512 & \multirow{2}{*}{\multicolumn{3}{|c|}{$\sum \varepsilon_{R}=0,31412327$}} \\
\hline 1996 & 11331722 & 0,002248481 & & & \\
\hline
\end{tabular}


Tabel 3. Prediksi banyaknya penduduk Sumatera Utara beserta Galat Relatif dengan menggunakan metode polinom newton gregory mundur.

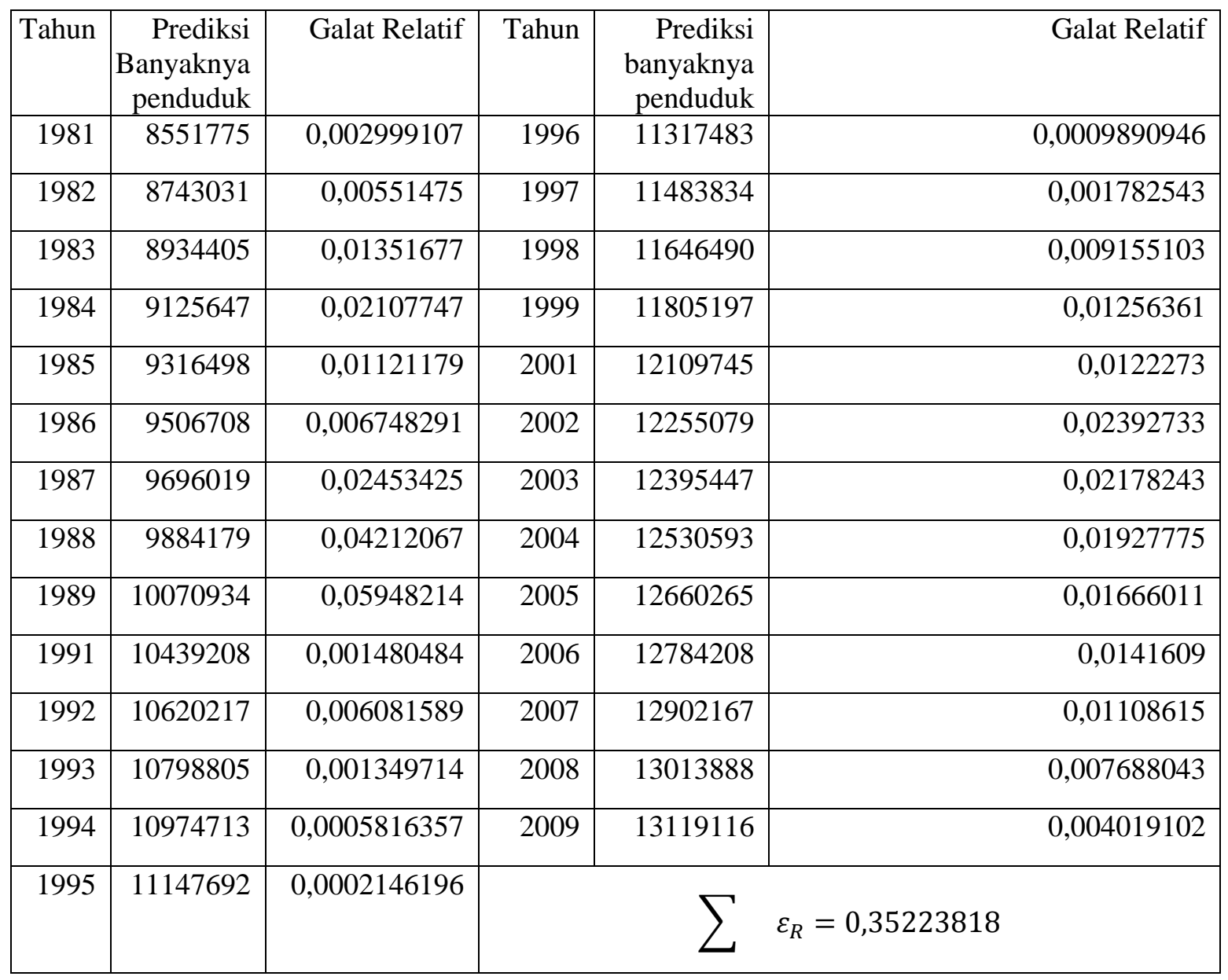

Prediksi banyaknya penduduk Sumatera Utara menggunakan metode polinom newton gregory maju dan polinom newton gregory mundur ditampilkan pada table 2 dan tabel 3 yang tidak memberikan hasil yang sama. Perolehan galat total metode newton gregory maju sebesar $\sum \quad \varepsilon_{R}=$ 0,31412327 sedangkan untuk metode polinom newton gregory mundur diperoleh nilai galat totalnya sebesar $\sum \varepsilon_{R}=$ 0,35223818 . Dari kedua galat tersebut diketahui bahwa galat total dengan metode newton gregory maju lebih kecil dari galat total dengan metode polinom newton gregory mundur. Dengan demikian metode polinom newton gregory maju memiliki akurasi yang lebih baik.

\section{Metode Hamilton-Perry}

Prediksi penduduk dengan metode Hamilton-perry menggunakan data tahun
1990 dan 2000 digunakan sebagai training sedangkan data tahun 2010 sebagai testing. Sumber data berasal dari Badan Pusat Statistik Sumatera Utara yang ditampilkan pada tabel 1. Langkah pertama dalam metode Hamilton-Perry adalah mencari nilai CCR untuk penduduk usia 10-64 tahun dengan persamaan: ${ }_{n} C C R_{x+y}=$ ${ }_{n} P_{x+y, l} /{ }_{n} P_{x, b}$ dengan ${ }_{n} P_{x+y, l}$ penduduk usia $x+y$ sampai $x+y+n$ pada sensus tahun $l,{ }_{n} P_{x, b}$ adalah penduduk usia $x$ sampai $x+n$ pada sensus tahun $l$, dan $y=$ $l-b$. Misalkan terdapat data sensus penduduk tahun 1990 dan 2000, maka CCR untuk penduduk usia 20-24 tahun adalah: ${ }_{5} C C R_{20}={ }_{5} P_{20,2000} /{ }_{5} P_{10,1990}$

Kemudian prediksi metode Hamilton-Perry untuk penduduk usia 10-64 tahun menggunakan persamaan: ${ }_{n} P_{x+y, t}=$ ${ }_{n} C C R_{x+y} \cdot{ }_{n} P_{x, l}$

dengan y adalah banyaknya tahun $l$ dan $t$. Misalkan dengan menggunakan data 
sensus penduduk tahun 1990 dan 2000, maka prediksi penduduk usia 20-24 tahun pda tahun 2010: ${ }_{5} P_{20,2010}={ }_{5} C C R_{20} \cdot{ }_{5} P_{10,2000}$

Sementara prediksi penduduk 65 tahun ke atas menggunakan persamaan:

$P_{65+, 2000}=\left(P_{65+, 2000} / P_{55,1990}\right) P_{55,2000}$

Untuk memprediksi penduduk usia 0-4 tahun, maka CWR (child woman ratio) adalah jumlah penduduk usia 0-4 tahun dibagi dengan jumlah penduduk perempuan usia 15-44, lalu untuk memprediksi penduduk usia 5-9 tahun, CWR diartikan sebgai perbandingan antara penduduk usia 5-9 tahun terhadap jumlah penduduk usia 20-49 tahun. Berikut implementasi dari cara Shryock dan Siegel (1973) untuk prediksi penduduk usia 0-4 tahun dan 5-9 tahun menggunakan persamaan:

Penduduk perempuan usia 0-4 tahun:

$$
\begin{aligned}
& { }_{5} F P_{0, t}=\left({ }_{5} F P_{0, l} /\right. \\
& \left.{ }_{30} F P_{15, l}\right){ }_{30} F P_{15, t}
\end{aligned}
$$

Penduduk laki-laki usia 0-4 tahun: ${ }_{5} M P_{0, t}=\left({ }_{5} M P_{0, l} /\right.$ $\left.{ }_{30} F P_{15, l}\right){ }_{30} F P_{15, t}$

Penduduk perempuan usia 5-9 tahun: ${ }_{5} F P_{5, t}=\left({ }_{5} F P_{5, l} /\right.$ $\left.{ }_{30} F P_{20, l}\right){ }_{30} F P_{20, t}$

Penduduk laki-laki usia 5-9 tahun: ${ }_{5} M P_{5, t}=\left({ }_{5} M P_{5, l} /\right.$ $\left.{ }_{30} F P_{20, l}\right){ }_{30} F P_{20, t}$

Hasil perhitungan CCR dan prediksi penduduk sumatera utara tahun 2010 menggunakan metode Hamilton-perry ditampilkan pada tabel 4.

Tabel 4. Hasil perhitungan CCR dan prediksi penduduk sumatera utara tahun 2010 menggunakan metode Hamilton-perry

\begin{tabular}{|r|r|r|r|r|r|r|r|r|}
\hline $\begin{array}{r}\text { Kelom } \\
\text { pok } \\
\text { umur }\end{array}$ & \multicolumn{1}{|l|}{ CCR } & \multicolumn{2}{|c|}{2010 (prediksi Hamilton-perry) } & \multicolumn{3}{|c|}{ SP 2010 } \\
\cline { 2 - 9 } & aki-laki & mpuan & Laki-laki & perempuan & total & Laki-laki & Perempuan & total \\
\hline $5-9$ & & & 340865,56 & 788035,54 & 1628901,10 & 673600 & 646600 & 1320200 \\
\hline $10-14$ & 1,064 & 1,061 & 754482,4 & 723632,28 & 1478114,68 & 688300 & 663500 & 1351800 \\
\hline $15-19$ & 0,883 & 0,925 & 656069 & 657305 & 1313374 & 725500 & 700300 & 1425800 \\
\hline $20-24$ & 0,744 & 0,827 & 531067,2 & 562360 & 1093427,2 & 677000 & 636800 & 1313800 \\
\hline $25-29$ & 0,757 & 0,810 & 506660,1 & 536949 & 1043609,1 & 604600 & 585600 & 1190200 \\
\hline $30-34$ & 0,942 & 0,850 & 506419,2 & 481610 & 988029,2 & 481500 & 506400 & 987900 \\
\hline $35-39$ & 0,953 & 0,881 & 432757,3 & 428342,2 & 861099,5 & 418500 & 456000 & 974500 \\
\hline $40-44$ & 0,926 & 0,903 & 384567,8 & 390276,6 & 774844,4 & 390800 & 413500 & 804300 \\
\hline $45-49$ & 0,877 & 0,886 & 329225,8 & 339958,2 & 669,184 & 354000 & 367300 & 721300 \\
\hline $50-54$ & 0,927 & 0,936 & 305353,8 & 302047,2 & 607401 & 306000 & 305500 & 611500 \\
\hline $55-59$ & 0,773 & 0,759 & 197197 & 184756 & 381953 & 230100 & 225500 & 456600 \\
\hline $60-64$ & 0,693 & 0,746 & 123700,5 & 131072,2 & 254772,7 & 152200 & 157800 & 310000 \\
\hline $65+$ & 1,819 & 2,003 & 343427,2 & 444465,7 & 787892,9 & 253400 & 300900 & 554300 \\
\hline & & & 330038,66 & 6836438,90 & 13666507,56 & 6616000 & 6601600 & 13217600 \\
\hline
\end{tabular}


Hasil prediksi penduduk tahun 2010 menggunakan metode Hamilton-Perry secara agregat menghasilkan nilai yang lebih besar daripada nilai aktualnya. Jika diperinci seberapa besar selisih antara prediksi terhadap aktualnya ditampilkan pada tabel 5.

Tabel 5. Selisih absulut antara prediksi penduduk terhadap penduduk actual

\begin{tabular}{|r|r|r|}
\hline Kelompok umur & \multicolumn{2}{|r|}{$\mid$ actual - prediksi } \\
\hline $0-4$ & 167265,56 & Perempuan \\
\hline $5-9$ & 257745,79 & 229728,98 \\
\hline $10-14$ & 66182,4 & 60132,28 \\
\hline $15-19$ & 69431 & 42995 \\
\hline $20-24$ & 145932,8 & 74440 \\
\hline $25-29$ & 97939,9 & 48651 \\
\hline $30-34$ & 24919,2 & 24790 \\
\hline $35-39$ & 14257,3 & 27657,8 \\
\hline $40-44$ & 6232,2 & 23223,4 \\
\hline $45-49$ & 24774,2 & 27341,8 \\
\hline $50-54$ & 646,2 & 3452,8 \\
\hline $55-59$ & 32903 & 40744 \\
\hline $60-64$ & 28499,5 & 26727,8 \\
\hline $65+$ & 90027,2 & 143565,7 \\
\hline jumlah & 1026756,25 & 914886,1 \\
\hline & & \\
\hline
\end{tabular}

Selisih absulut terendah untuk penduduk laki-laki dan perempuan terjadi pada usia 50-54 tahun yaitu 646,2 dan 3452,8. Setiap prediksi pasti ada penyimpangan terhadap data aktualnya, namun pada metode Hamilton-perry membutuhkan data yang minim dibandingkan metode lainnya dan proses perhitungannya sangat mudah dilkukan. Kemudian akan penulis bandingkan hasil prediksi yang dirounding (dibulatkan) dengan yang tidak dirounding dan hasilnya akan ditampilkan pada tabel 6 .

Tabel 6. Hasil prediksi penduduk menggunakan metode Hamilton perry antara nilai yang dibulatkan dan nilai yang tidak dibulatkan.

\begin{tabular}{|r|r|r|r|r|r|r|}
\hline ppok umur & \multicolumn{4}{|c|}{2010 (tidak dibulatkan) } & \multicolumn{3}{|r|}{2010 (dibulatkan) } \\
\hline & Laki-laki & Perempuan & Total & Laki-laki & Perempuan & Total \\
\hline $0-4$ & 840865,56 & 788035,54 & 1628901,10 & 840866 & 788036 & 1628902 \\
\hline $5-9$ & 91824579 & 865628,98 & 1783874,78 & 918246 & 865629 & 1783875 \\
\hline $10-14$ & 754482,4 & 723632,28 & 1478114,68 & 754482 & 723632 & 1478114 \\
\hline
\end{tabular}




\begin{tabular}{|r|r|r|r|r|r|r|}
\hline $15-19$ & 656069 & 657305 & 1313374 & 656069 & 657305 & 1313374 \\
\hline $20-24$ & 531067,2 & 562360 & 1093427,2 & 531067 & 562360 & 1093427 \\
\hline $25-29$ & 506660,1 & 536949 & 1043609,1 & 506660 & 536949 & 1043609 \\
\hline $30-34$ & 506419,2 & 481610 & 988029,2 & 506419 & 481610 & 988029 \\
\hline $35-39$ & 432757,3 & 428342,2 & 861099,5 & 432757 & 428342 & 861099 \\
\hline $40-44$ & 384567,8 & 390276,6 & 774844,4 & 384568 & 390277 & 774845 \\
\hline $45-49$ & 329225,8 & 339958,2 & 669184 & 329226 & 339958 & 669184 \\
\hline $50-54$ & 305353,8 & 302047,2 & 607401 & 305354 & 302047 & 607401 \\
\hline $55-59$ & 197197 & 184756 & 381953 & 197197 & 184756 & 381953 \\
\hline $60-64$ & 123700,5 & 131072,2 & 254772,7 & 123701 & 131072 & 254773 \\
\hline $65+$ & 343427,2 & 444465,7 & 787892,9 & 343427 & 444466 & 787893 \\
\hline & 6830039 & 6836439 & 13666508 & 6830039 & 6836440 & 13666509 \\
\hline
\end{tabular}

Jika diperhatikan tabel 6 , terdapat secara agregat perbedaan antara nilai yang tidak dibulatkan dan nilai yang dibulatkan pada agrgat jumlah penduduk perempuan. Jumlah penduduk perempuan jika tidak dibulatkan mencapai 6836439 dan jika dibulatkan mencapai 6836440 terdapat selisih satu. Oleh karena itu hasil pembulatan perlu diadjusment dalam kasus ini perlu dikurangi satu untuk penduduk perempuan. Dalam hal ini penulis memilih penduduk usia 60-64 tahun. Nilai pembulatan pada penduduk perempuan usia 60-64 adalah 131072 harus dikurangi satu sehingga menjadi 131071. Dengan demikian prediksi penduduk tahun 2010 dengan menggunakan metode Hamilton-perry setelah dilakukan adjustment terhadap rounding error ditampilkan pada tabel 7.

Tabel 7. Hasil prediksi penduduk menggunakan metode Hamilton-perry setelah diadjustment.

\begin{tabular}{|r|r|r|r|}
\hline Kelompok umur & \multicolumn{3}{|c|}{2010 ( prediksi Hamilton-perry setelah diadjustment) } \\
\hline & Laki-laki & Perempuan & Total \\
\hline $0-4$ & 840866 & 788036 & 1628902 \\
\hline $5-9$ & 918246 & 865629 & 1783875 \\
\hline $10-14$ & 754482 & 723632 & 1478114 \\
\hline $15-19$ & 656069 & 657305 & 1313374 \\
\hline $20-24$ & 531067 & 562360 & 1093427 \\
\hline $25-29$ & 506660 & 536949 & 1043609 \\
\hline $30-34$ & 506419 & 481610 & 988029 \\
\hline $35-39$ & 432757 & 428342 & 861099 \\
\hline $40-44$ & 384568 & 390277 & 774845 \\
\hline $45-49$ & 329226 & 339958 & 669184 \\
\hline
\end{tabular}




\begin{tabular}{|r|r|r|r|}
\hline $50-54$ & 305354 & 302047 & 607401 \\
\hline $55-59$ & 197197 & 184756 & 381953 \\
\hline $60-64$ & 123701 & 131071 & 254772 \\
\hline $65+$ & 343427 & 444466 & 787893 \\
\hline & 6830039 & 6836439 & 13666508 \\
\hline
\end{tabular}

\section{KESIMPULAN DAN SARAN}

\section{Kesimpulan}

1. Untuk Hamilton-perry, penerapan metodenya mudah dilakukan karena proses perhitungannya yang tidak rumit dan data yang digunakan sebagai bahan prediksi sangat minim, tetapi nilai prediksi menghasilkan nilai tidak bulat sehingga perlu dibulatkan namun ketika nilai sudah dibulatkan terdapat selisih antara nilai tidak dibulatkan dengan nilai yang dibulatkan ecara agrgat. Oleh karena itu dibutuhkan adjustment pada nilai hasil pembulatan berdasarkan nilai tidak dibulatkan. Kemudian berdasarkan uji coba agregat prediksi penduduk menggunakan metode Hamilton-perry menhgasilkan nilai yang lebih tinggi daripada nilai aktualnya.

Peneliti mengucapkan terimakasih atas pendanaan penelitian dosen pemula kepada Direktorat Riset dan Pengabdian

\section{DAFTAR PUSTAKA}

1. Badan Pusat Statistik, (2003). Sensus Penduduk.

2. Munir, R. (2003). Metode Numerik, Informatika Bandung, Bandung

3. Lembaga Demografi, (2004). Dasar-dasar demografi, Jakarta: Fakultas Ekonomi Universitas Indonesia.

4. Herwanto, E., (2010). Prediksi Banyaknya Penduduk Sulawesi Tengah Dengan Menggunakan Metode Polinom Newton Gregory Maju, Fakultas Matematika dan Ilmu Pengetahuan Alam Universitas Tadulako, Sulawesi Tengah, Palu.

5. Martina, A., (2017). Metode Numerik Interpolasi Polinom Newton Gregory Mundur, Fakultas Keguruan dan Ilmu Pendidikan Universitas PGRI Yogyakarta, D.I Yogyakarta.
2. Untuk metode polinom newton gregory maju dan polinom newton gregory mundur diperoleh masing-masing galat relatif totalnya adalah $\sum \quad \varepsilon_{R}=0,31412327$ dan $\sum \quad \varepsilon_{R}=0,3522818$. Dari kedua galat relatif tersebut diketahui bahwa galat total untuk metode polinom newton gregory maju lebih kecil dari galat total untuk metode polinom newton gregory mundur. Dengan demikian metode polinom newton gregory maju memiliki akurasi yang lebih baik.

\section{Saran}

Untuk penelitian selanjutnya dapat dibandingkan antara metode polinom newton gregory maju, polinom newton gregory mundur dan metode Hamilton-perry dengan metode lainnya.

\section{UCAPAN TERIMAKASIH}

Masyarakat (DRPM) kementrian riset dan teknologi dengan nomor kontrak T/49/L1.3.1/PT.01.03/2019.

6. Pratiwi, G.A. (2017). Aplikasi metode polinom newton Gregory maju dan polinom Gregory mundur dalam memprediksi banyaknya penduduk Sulawesi tengah, JIMT 2017, vol:14, pp.152-158.

7. Swanson, A.D. \& Tayman, J. (2016). A long termtest of the accuracy of the HamiltonPerry Method for forecasting state population by age. The frontlers of Applied demography, Vol9 of the series Applied Demography series pp.n491-513.

8. Swanson, al at (2010). Forecasting the populations of census tracts by age and sex: an example of the Hamilton-Perry Method in action. Population research and policy review: in cooperation with the southem Demographic Association, 29(1)

9. Muhammad Fajar (2017). Penerapan Metode Hamilton-perry untuk proyeksi Penduduk, Doi:10.13140/Rg.2.2.12 282.08 
